\title{
Introduction To Hearing And Speech Rehabilitation
}

\author{
Ahmet Kasumović \\ ahmetkasumovic@gmail.com
}

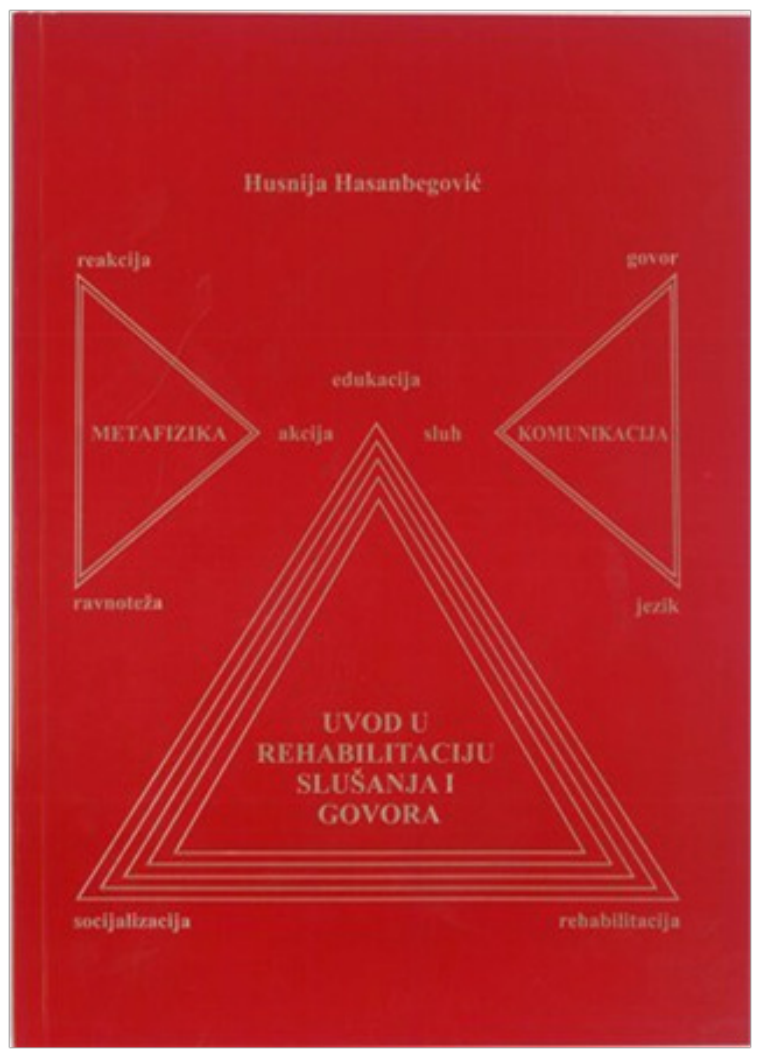

Rehabilitation of hearing and speech represents a theory that needs to be confirmed, and also the practice, also a process which is in continuous progress. It is simultaneously a science (research activity), the profession, school subject, issue, principle and method. Continuously be upgraded, and the search for new knowledge. Deaf and severely hearing-impaired people are often deprived from birth hearing and listening skills, and thus the ability to successfully speaking, standard, oral-vocal speech, language or hearing. In the absence of hearing, their psychological structure has been changed, so methods of learning that are used to hearing children, for them have no or have very small use. Therefore, the rehabilitation theory and practice need to seek for new methods, programming models, test materials, and researching the effectiveness of these methods in teaching speech and language skills of hearing impaired population. In this book, besides the general scientific, theoretical and practical regularity, related to the subject of Speech and Hearing Rehabilitation, are described the anatomical and physiological basis of auditory organs, and organs to speak, and the essential characteristics of the hearing impairment, ways of communications, education and rehabilitation in relation to general characteristics of hearing impaired persons. It describes the communication of the deaf and hard of hearing as a determinant of rehabilitation, rehabilitation of hearing as a determinant of learning speech and language, speech and language as a determinant of communication and speech-language education as a determinant of rehabilitation. The importance of programming in the rehabilitation of hearing and speech is highlighted, and new, paradigmatic-pragmatic methods in speechlanguage rehabilitation of the deaf and severely hard of hearing people is described. From a scientific point of view, programming of dynamic rehabilitation content, has or may have a direct scientific contribution to the psychological development of deaf and severely hearingimpaired population. By development of deaf person, the possibility of regulating the relation between a deaf person-society and vice versa is opened. The results of research of the use of programmed dynamic content in rehabilitation showed a significant movement to improve linguistic competence and quality in the communication of the deaf and severely hard of hearing people with hearing world. Dynamic methodological approaches in speech-language education of deaf and hearing-impaired children, it provides easier learning of all elements of speech and language, primarily phonology and morphology, and semantics, syntax, grammar and language of the hearing community. 


\section{Bilingual Glossary}

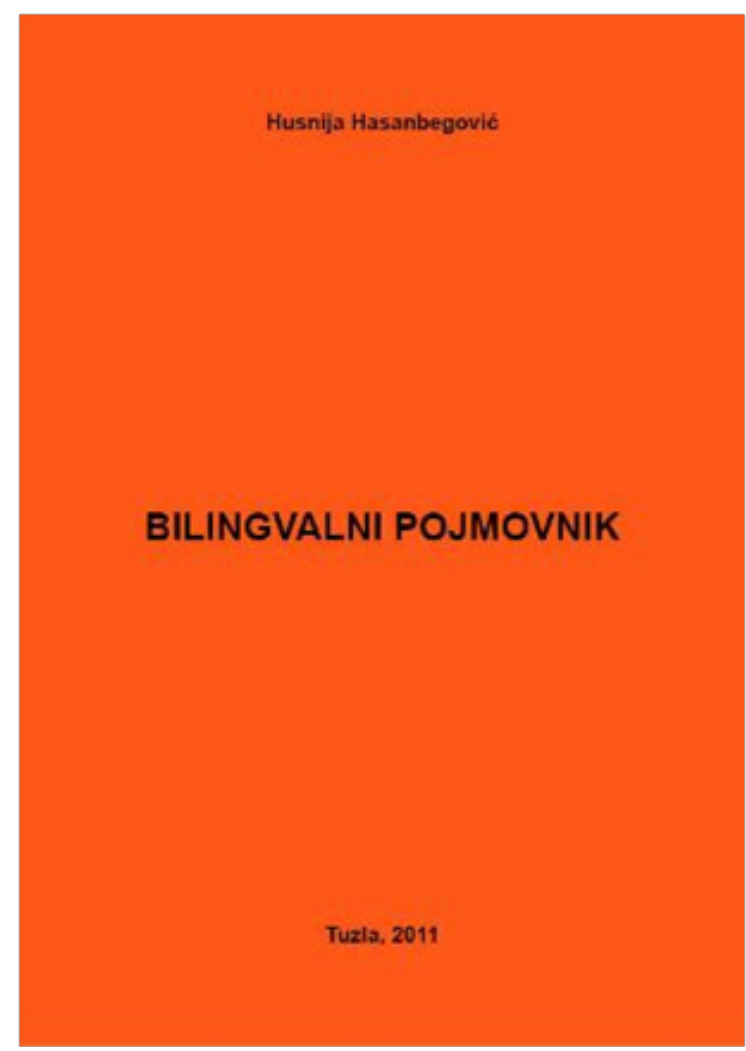

The problem of deafness and its effects on communication exists throughout the history of mankind until today, when going expansion of technological development. New technologies in the development of hearing aids in recent decades, have significantly contributed to better hearing-verbal communication of deaf people, and therefore more successful learning and socialization. However, it is still deaf children in the adoption of concepts predominantly rely on visual perception, making rehabilitation of hearing and speech occupies a central role in learning. For successful rehabilitation and education, deaf children need adequate professional support, through a very complex, diverse and programmed treatments, and teaching-didactic materials. Experts in practice, making great efforts to make these children passed the basic concepts related to practical situations in everyday life. Therefore, for this population of children is essential methodology of teaching. Bilingual glossary, as well as support for the visual approach to learning is the original teaching tool, which is the conceptualization svojojoj didactic practicum. Practicum provides obvious and intellectually more active way of learn- ing concepts, and can serve as a didactic-teaching aid in speech training, a final verbal testimony and speech production of deaf children. Bilingual dictionary is a glossary of selected terms Bosnian and sign language, presented drawings of the language movement and associative drawings for a better understanding of the concepts written in Bosnian and English. This way of learning to maximize the semantics, improves linguistic competency deaf students, which has an excellent glossary of methodological value in meeting the complex demands of educational audiology. Practicum provides an opportunity to connect reading and writing with comprehension in children who can not remember hearing the term read. The glossary is primarily intended for deaf children, and may serve a rehabilitative and educational audiologists, speech therapists, and parents or guardians of deaf children, in order to better understand the cognitive problems of deaf children, and thus access to finding ways to adapt the child and the family of a different form of learning.

Prof.dr. Ahmet Kasumović 